Research Article

\title{
Design Forces of Horizontal Braces Unlocated at Middle of Columns considering Random Initial Geometric Imperfections
}

\author{
Jinyou Zhao $\mathbb{D}$, Junming Wei $\mathbb{D}$, and Jun Wang $(\mathbb{D}$ \\ School of Civil Engineering, Northeast Forestry University, Harbin 150040, China \\ Correspondence should be addressed to Junming Wei; 2019110604@nefu.edu.cn
}

Received 1 June 2021; Revised 9 September 2021; Accepted 27 October 2021; Published 29 November 2021

Academic Editor: Bruno Briseghella

Copyright ( $\odot 2021$ Jinyou Zhao et al. This is an open access article distributed under the Creative Commons Attribution License, which permits unrestricted use, distribution, and reproduction in any medium, provided the original work is properly cited.

\begin{abstract}
The horizontal bracing forces of column-bracing systems derived from past studies and current design codes were considered only located at middle of columns. Actually, the horizontal braces used to reduce the out-of-plane effective column lengths are frequently designed not to locate at middle of columns. In this paper, a large number of column-bracing systems with the horizontal braces unlocated at middle of columns were modelled and analyzed using the finite element method, in which the random initial geometric imperfections of both the columns and the horizontal braces unlocated at middle of columns were well considered by the Monte Carlo method. Based on the numerical calculations, parametric analysis, and probability statistics, the probability density function of the horizontal bracing forces was found, so that the corresponding design forces of horizontal braces unlocated at middle of columns were proposed which were compared with the design mid-height horizontal bracing forces in the previous study and the relevant codes. The results indicate that the design forces of the horizontal braces located at 0.6 column height are smaller than the mid-height horizontal bracing forces in the previous study while the design forces of horizontal braces located at 0.7 column height are larger than the mid-height horizontal bracing forces in the previous study. The proposed design forces of the horizontal braces located and unlocated at middle of columns are both smaller than the mid-height horizontal bracing forces stipulated in GB500172017, Eurocode 3-1992, and AS4100-1998. The above conclusions provide references for the engineering applications and further related code revisions.
\end{abstract}

\section{Introduction}

One of the most important functions of bracing members in structural systems is to provide intermediate lateral support to compression members for enhancing their stability [1]. The brace strength requirements to achieve a specified increase in the buckling strengths of the braced columns have generally been developed from a single column-brace model [2-4] to column-bracing systems [5-8]. Among the above studies, the horizontal braces used to reduce the out-of-plane effective column lengths were assumed to be located at middle of columns. In engineering practice, the above horizontal braces are frequently designed to be located a bit higher than middle of columns, but no significant definitive research has been performed for the design forces of the horizontal braces unlocated at middle of columns.

In past studies on the mid-height horizontal bracing forces for column-bracing systems $[7,8]$, the random initial geometric imperfections of both the columns and the horizontal braces were well considered by the Monte Carlo method. The research results showed that the random combination of the initial geometric imperfections between the columns and the horizontal braces has a favourable effect on the bracing forces as it leads to the randomness of the mid-height horizontal bracing forces in compression or tension when the ultimate load of the braced columns is reached. Therefore, in order to estimate and to ensure the accuracy of the design forces of the horizontal braces unlocated at middle of columns, it is still necessary to 
consider the effects of uncertainties of initial geometric imperfections [9].

Bach et al. utilized the Bayesian optimization method to solve multi-objective robust design optimization problems of steel frames under aleatory uncertainty in external loads and material properties [10]. Reza et al. applied the uniform deformation method to obtain the optimal distribution of dampers for reducing the seismic response of steel frames with multi-degree-of-freedom [11]. Bergami and Nuti employed the capacity spectrum method to establish a displacement-based procedure applied to design dissipative bracings for the seismic protection of frame structures [12]. In this paper, a large number of column-bracing systems with the horizontal braces unlocated at middle of columns have been carried out by second-order analysis using ANSYS, in which the initial geometric imperfections of both the columns and the horizontal braces were randomly sampled according to the Monte Carlo method. Moreover, the probability density function of the design forces of the horizontal braces unlocated at middle of columns was found by probability statistics, so that the corresponding design forces of the horizontal braces unlocated at middle of columns were also proposed which were compared with the design mid-height horizontal bracing forces in the previous study and the relevant codes. Based on the research results, recommendations for the revision of relevant codes were provided.

\section{Analytical Model and Parametric Design}

The analytical models of column-bracing systems with the horizontal braces unlocated at middle of columns are shown in Figure 1. The $n$-columns in the row which are equally spaced and simply supported have the same vertical axial load $P$ at the top of the columns, and the horizontal braces used to reduce the out-of-plane effective column lengths are located at 0.6 column height or 0.7 column height, respectively. The cross-sectional areas of the columns are the same and are denoted by $A_{c}$; the cross-sectional areas of the horizontal braces at 0.6 column height or 0.7 column height are the same and are denoted by $A_{m}$, the cross-sectional areas of the horizontal braces at the top of the columns are the same and are denoted by $A_{t}$, and $A_{m}$ is equal to $A_{t}$; the crosssectional areas of the diagonal bracings are the same and are denoted by $A_{d}$.

The parameter selection of the analytical models is mainly based on reference [8]: the half slenderness ratio of the column about the minor axis $\lambda_{c}$, the slenderness ratio of the horizontal brace $\lambda_{b}$, and the ratio of the horizontal brace length over the column height $b / L$. In engineering practice, the commonly used parameters are $b=6 \mathrm{~m}, 50 \leq \lambda_{c} \leq 100$, $100 \leq \lambda_{b} \leq 200$, and $0.4 \leq b / L \leq 0.7$.

A biaxially symmetric I-section is used for the column section whose flexural buckling along the longitudinal direction of the building occurs about the minor axis of the column. The cross-sectional areas of the columns are equal to $250 \mathrm{~cm}^{2}$, and the geometric dimensions of the columns are shown in Table 1.
A circular tube section is used for the horizontal brace section. According to the ultimate loads of the braced columns and the different number $n$ of the braced columns, the horizontal braces are designed and the geometric dimensions of the horizontal braces for $n=6$ are shown in Table 2.

The circular solid bars are used for the diagonal bracings. According to the horizontal bracing forces, the diagonal bracings are designed against tension only and the crosssectional areas of the diagonal bracings $A_{d}$ for $n=6$ are shown in Table 1.

\section{Random Combination of Initial Geometric Imperfections}

3.1. The Monte Carlo Method. The Monte Carlo method is also called the statistical testing method which can be used to solve complex engineering problems containing random variables by numerical simulation and probability statistics [13]. According to the Monte Carlo method, the probability models of the initial imperfections of the columns and the braces are set up, all of which are normally distributed. The probability distributions of the important parameters in the problems can be established based on the results of numerical simulation [14]. The Monte Carlo method can resolve large sample problems with small sample sizes sampled randomly, and it is considered that the results of the Monte Carlo method are credible as long as a sufficient number of sample sums are sampled and the simulation tests are accurate. The specific process of the Monte Carlo method applied to the research in this paper is shown in Figure 2.

3.2. Probability Distribution Model of Initial Geometric Imperfections. The randomness of the initial geometric imperfections in a structure is caused by the sum of many independent random variables, and each random variable can be represented by a normal distribution according to the Monte Carlo method [15]. Given that the number of the braced columns is $n, \delta_{0 i}$ is the initial bow imperfection of the $i$ th column, and its probability distribution can be written as

$$
P_{i}\left(\delta_{0 i}\right)=\frac{1}{\sqrt{2 \pi} \sigma_{1}} e^{-\left(\left(\delta_{0 i}-\mu_{1}\right)^{2} / 2 \sigma_{1}^{2}\right)}, \quad i=1,2, \ldots, n .
$$

Given that $\Delta_{0 i}$ is the initial sway imperfection of the $i$ th column, its probability distribution can be written as

$$
P_{i}\left(\Delta_{0 i}\right)=\frac{1}{\sqrt{2 \pi} \sigma_{2}} e^{-\left(\left(\Delta_{0 i}-\mu_{2}\right)^{2} / 2 \sigma_{2}^{2}\right)}, \quad i=1,2, \ldots, n .
$$

Given that $u_{0 i}$ is the initial imperfection of the $i$ th horizontal brace unlocated at middle of columns, its probability distribution can be written as

$$
P_{i}\left(u_{0 i}\right)=\frac{1}{\sqrt{2 \pi} \sigma_{3}} e^{-\left(\left(u_{0 i}-\mu_{3}\right)^{2} / 2 \sigma_{3}^{2}\right)}, \quad i=1,2, \ldots, n-1 .
$$




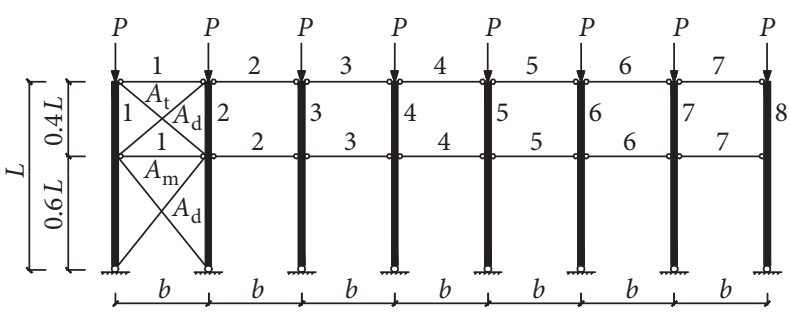

(a)

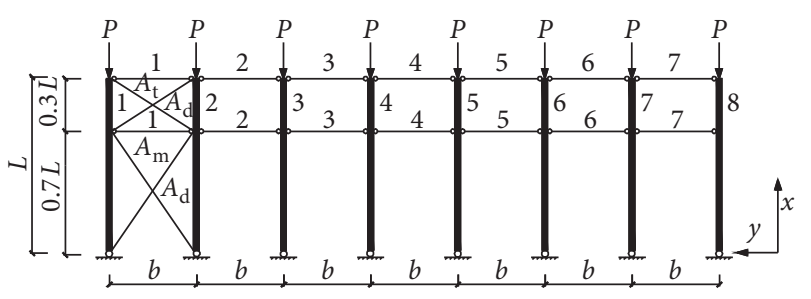

(b)

Figure 1: Analytical models of column-bracing system with the horizontal braces unlocated at middle of columns. (a) Horizontal braces located at $0.6 L$. (b) Horizontal braces located at $0.7 L$.

TABLE 1: Geometric dimensions of column sections.

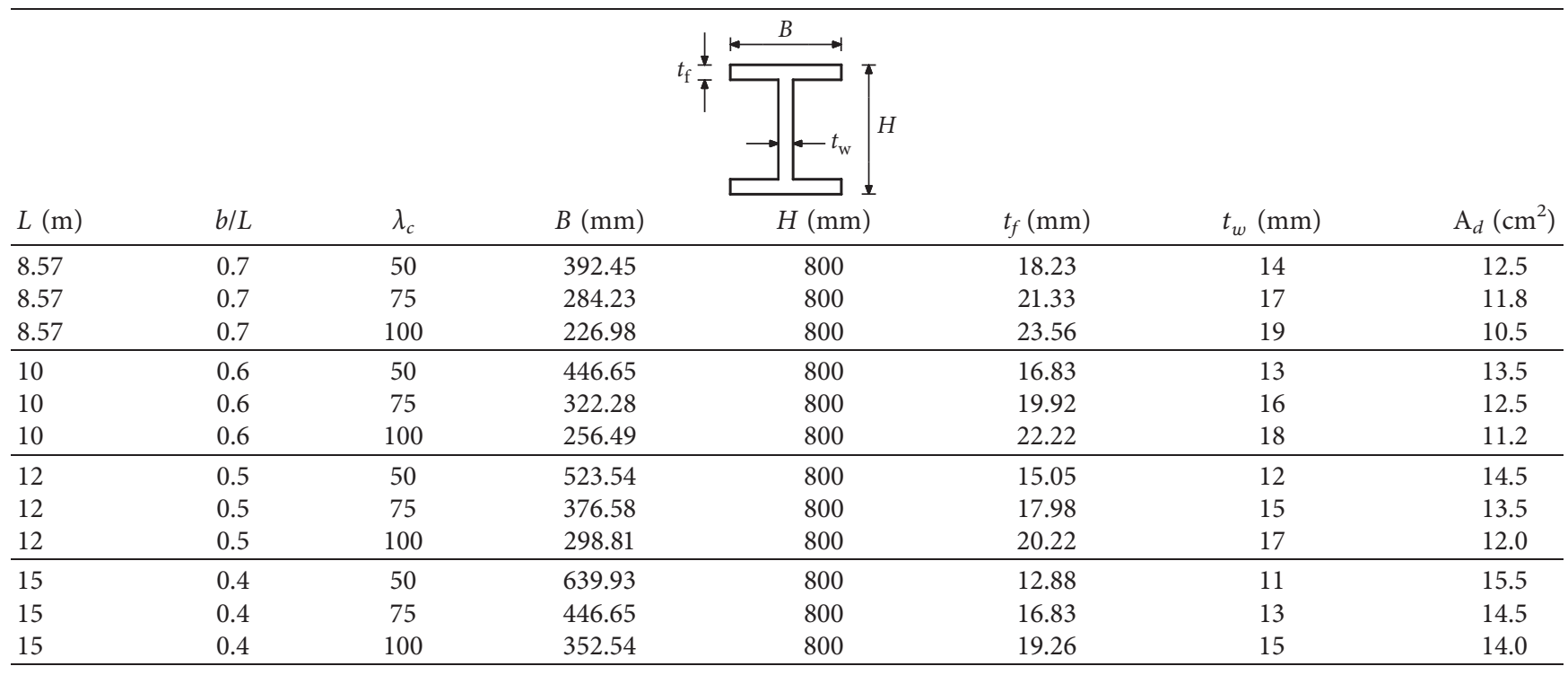

Note. $H, B$-height and width of I-section, respectively; $t_{w}, t_{f}$-thickness of web and flange, respectively; $A_{d}$-the cross-sectional area of the diagonal bracings.

TABLE 2: Geometric dimensions of horizontal brace sections.

\begin{tabular}{|c|c|c|c|c|}
\hline$\lambda_{c}$ & $\lambda_{b}$ & $A_{m} / A_{t}\left(\mathrm{~cm}^{2}\right)$ & $D_{b}(\mathrm{~mm})$ & $t_{b}(\mathrm{~mm})$ \\
\hline \multirow{5}{*}{50} & 100 & 28 & 169.62 & 5.25 \\
\hline & 125 & 35 & 135.52 & 8.22 \\
\hline & 150 & 44 & 112.45 & 12.46 \\
\hline & 175 & 55 & 95.22 & 18.39 \\
\hline & 200 & 66 & 80.77 & 26.01 \\
\hline \multirow{5}{*}{75} & 100 & 27 & 169.63 & 5.07 \\
\hline & 125 & 34 & 135.53 & 7.99 \\
\hline & 150 & 43 & 112.48 & 12.17 \\
\hline & 175 & 54 & 95.28 & 18.04 \\
\hline & 200 & 65 & 80.91 & 25.57 \\
\hline \multirow{5}{*}{100} & 100 & 24 & 169.65 & 4.50 \\
\hline & 125 & 32 & 135.56 & 7.51 \\
\hline & 150 & 42 & 112.51 & 11.88 \\
\hline & 175 & 53 & 95.35 & 17.69 \\
\hline & 200 & 64 & 81.01 & 25.14 \\
\hline
\end{tabular}

Note. $A_{m}, A_{t}$-area of brace at mid-height and top of column, respectively; $D_{b}$, $t_{b}$-diameter and thickness of circular tube section, respectively. 


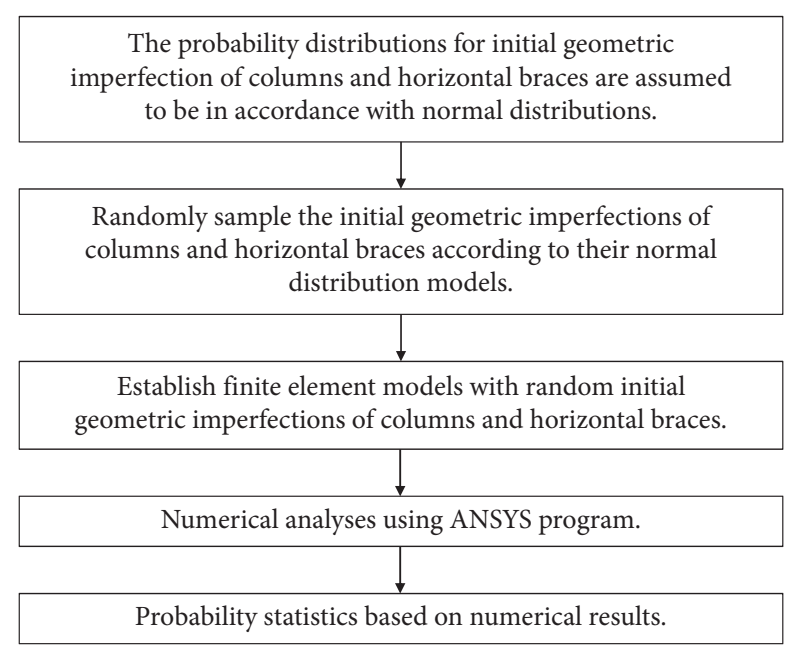

Figure 2: Specific process of the Monte Carlo method.

Given that $v_{0 i}$ is the initial imperfection of the $i$ th top horizontal brace, its probability distribution can be written as

$$
P_{i}\left(v_{0 i}\right)=\frac{1}{\sqrt{2 \pi} \sigma_{4}} e^{-\left(\left(v_{0 i}-\mu_{4}\right)^{2} / 2 \sigma_{4}^{2}\right)}, \quad i=1,2, \ldots, n-1,
$$

where $\mu_{1}=\mu_{2}=\mu_{3}=\mu_{4}=0, \sigma_{1}^{2}=\sigma_{2}^{2}=(L / 980)$, and $\sigma_{3}^{2}=\sigma_{4}^{2}$ $=(b / 980)$ [16]. The meanings of $L$ and $b$ are shown in Figure 1.

3.3. Random Initial Geometric Imperfection Equation. The initial bow imperfection of the $i$ th column is given as a halfsinusoid curve:

$$
\delta_{i}=\delta_{0 i} \sin \left(\frac{\pi x}{L}\right)
$$

The initial sway imperfection of the ith column is expressed as a straight line with the same slope:

$$
\Delta_{i}=\Delta_{0 i}\left(\frac{x}{L}\right)
$$

The initial bow imperfection of the $i$ th horizontal braces unlocated at middle of columns is given as a half-sinusoid curve:

$$
u_{i}=u_{0 i} \sin \left(\frac{\pi y}{b}\right)
$$

The initial bow imperfection of the $i$ th horizontal braces at the top of the columns is also given as a half-sinusoid curve:

$$
v_{i}=v_{0 i} \sin \left(\frac{\pi y}{b}\right),
$$

where $\delta_{0 i}$ and $\Delta_{0 i}$ are the initial bow and sway imperfections of the $i$ th column sampled by the Monte Carlo method, respectively, and $u_{0 i}$ and $v_{0 i}$ are the initial bow imperfections of the $i$ th horizontal braces unlocated at middle of columns or at the top of the columns sampled by the Monte Carlo method, respectively, and the meanings of $x$ and $y$ are shown in Figure 1.

\section{Finite Element Analysis considering Random Initial Geometric Imperfections}

4.1. Finite Element Model. The finite element models were built using the ANSYS program, in which the Beam 188 element was used to simulate the horizontal braces and the columns while the Link10 element was used to simulate the diagonal bracings. Hinged joints between the horizontal braces and the columns were formed by coupling their translational displacements at their nodes. There were 6 elements of each horizontal brace member and 12 elements per column member, and each diagonal bracing member used only one element. Based on equations (5)-(8), the coordinates of these elements were established which indicated the magnitudes and the directions of the random initial geometric imperfections.

\subsection{Random Sampling of Initial Geometric Imperfections.}

The tolerance of initial geometric imperfections is also mainly based on reference [8]. According to the "Code for Acceptance of Construction Quality of Steel Structures" in China (GB50205-2001) [17], the allowable fabrication deviations of columns for one-story steel structures are given as follows: the maximum value of initial bow imperfection should be less than $1 / 1200$ of the column height and the maximum value of initial sway imperfection should be less than 1/1000 of the column height. In addition, the allowable fabrication deviations of horizontal braces should be less than $1 / 750$ of the horizontal brace length.

According to the mean and the variance of the initial geometric imperfections, the initial geometric imperfections of the columns and the horizontal braces were randomly sampled by the function "Normrnd()" in the software MATLAB. In this study, 1.05 times the allowable fabrication deviations in GB50205-2001 were used for the initial geometric imperfection sample limits, and the sampled initial geometric imperfections must all be less than the limits.

4.3. Finite Element Analysis. In the finite element analysis, the constitutive relationship for steel was a bilinear strengthened elastic-plastic model, yield strength was $235 \mathrm{~N} /$ $\mathrm{mm}^{2}$, Young's modulus was $2.06 e^{5} \mathrm{~N} / \mathrm{mm}^{2}$, tangent modulus was $2.06 e^{3} \mathrm{~N} / \mathrm{mm}^{2}$, and Poisson's ratio was 0.3 . A nonlinear large displacement analysis was carried out using the arch-length method to find the maximum loads of the column-bracing systems which were taken as the strengths of the braced columns.

The column-bracing systems with the random initial geometric imperfections were analyzed for $n=4,6,8$, and 10 , in which the horizontal braces used to reduce the out-ofplane effective column lengths were located at 0.6 or 0.7 column height. When $n, \lambda_{c}$, and the horizontal brace location (at $0.6 L$ or $0.7 L$ ) were certain, there were twenty combinations for various values of $b / L$ and $\lambda_{b}$. For every 


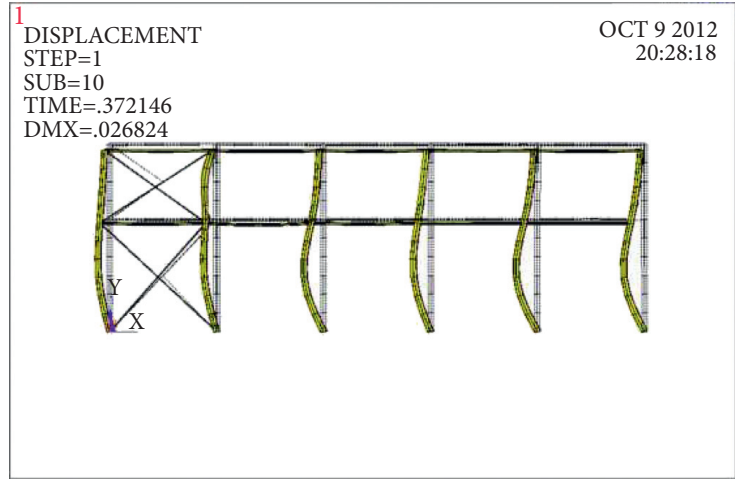

(a)

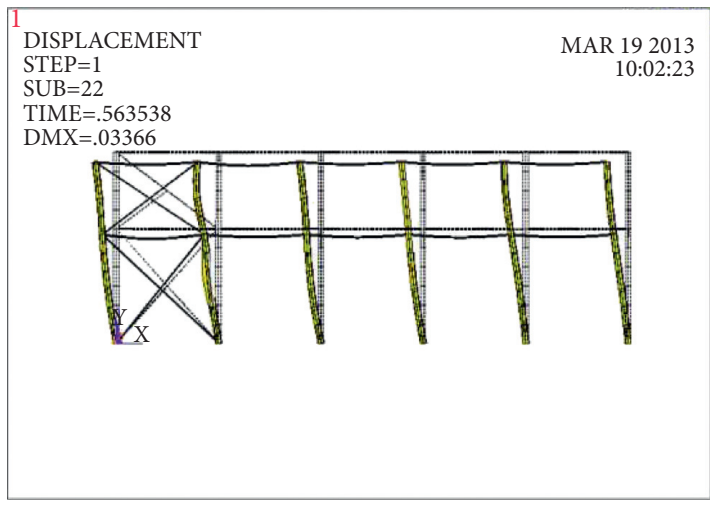

(c)

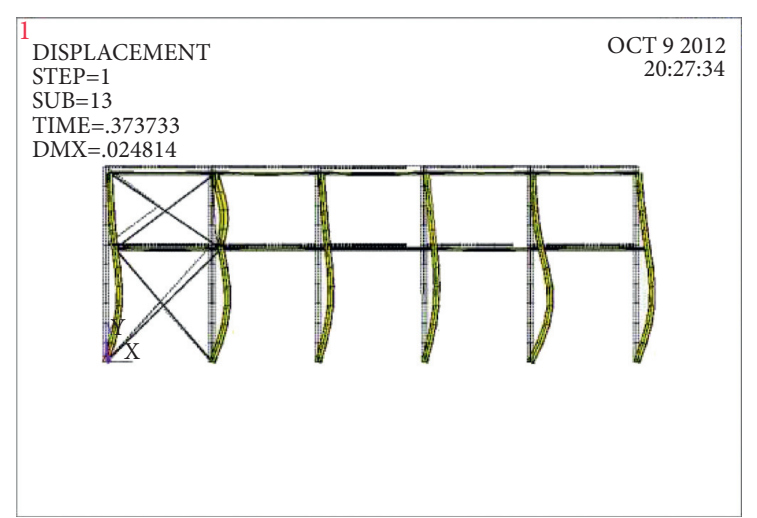

(b)

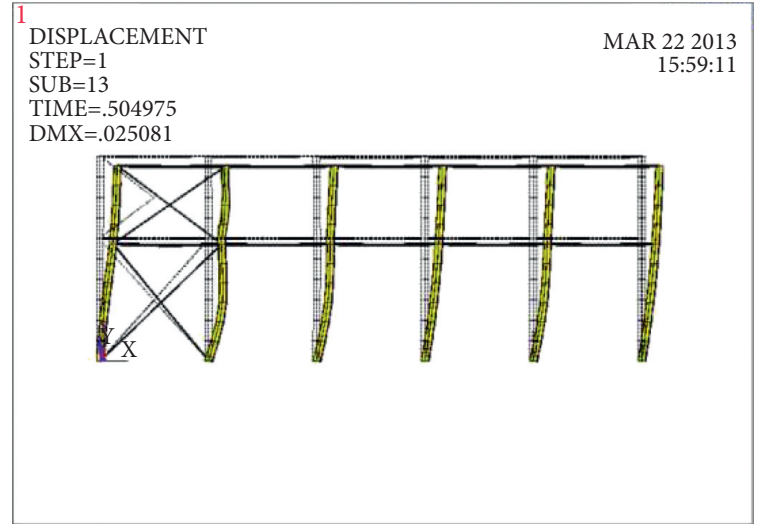

(d)

FIGURE 3: Instability deformation modes for horizontal braces located at $0.6 \mathrm{~L}$. (a) Non-sway instability (horizontal braces in compression). (b) Non-sway instability (horizontal braces in tension). (c) Sway instability (horizontal braces in compression or tension). (d) Sway instability (horizontal braces in compression or tension).

combination, fifty groups of the initial geometric imperfections of the columns and the horizontal braces were randomly sampled according to the Monte Carlo method. Therefore, there were one thousand combinations with random initial geometric imperfections for every certain constitution. The instability deformation modes could be obtained for every combination analyzed using the ANSYS program.

Figure 3 shows four kinds of instability modes for column-bracing systems with the horizontal braces located at 0.6 column height. For non-sway instability mode as shown in Figures 3(a) and 3(b), the maximum force of the horizontal braces located at $0.6 \mathrm{~L}$ is in compression and in tension, respectively; for sway instability modes as shown in Figures 3(c) and 3(d), the maximum force of the horizontal braces located at $0.6 \mathrm{~L}$ may be in compression or in tension but much more in compression. Similarly, column-bracing systems with the horizontal braces located at 0.7 column height also have four kinds of instability modes as shown in Figure 3, and the maximum force of the horizontal braces may be in compression or tension. The analysis results were found to be sensitive to both the magnitude and the direction of the random initial geometric imperfections of the columns and the horizontal braces.

\section{Probability Statistics of Numerical Results}

5.1. Probability Density Figures of F/P. F was defined as the maximum force of the horizontal braces unlocated at middle of columns induced by the ultimate load $P$ of the braced columns, and then the ratio $F / P$ was obtained for the horizontal braces located at $0.6 \mathrm{~L}$ or $0.7 \mathrm{~L}$, respectively. Considering the combination of $n=4,6,8,10$ and $\lambda_{c}=50$, 75,100 , twelve groups of $F / P$ ratios were obtained, respectively, when the horizontal braces are located at $0.6 \mathrm{~L}$ or $0.7 \mathrm{~L}$, respectively. As above mentioned, there are one thousand numerical results for every certain combination between $n$ and $\lambda_{c}$, which are directly affected by the random initial geometric imperfections of both the columns and the horizontal braces. Because of the randomness of the initial geometric imperfections of both the columns and the horizontal braces, the numerical results of $F / P$ obviously have randomness. Hence, numerical results were analyzed with probability statistics.

As an illustration, the results of twelve groups' $F / P$ ratios for the horizontal braces located at $0.6 \mathrm{~L}$ and $0.7 \mathrm{~L}$ are presented in Figures 4 and 5, respectively. In these figures, the sign of abscissas is defined as follows: $F / P$ is positive when $F$ is in compression while it is negative when $F$ is in 


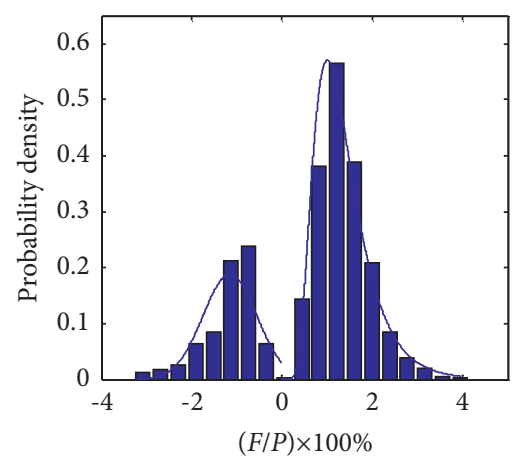

(a)

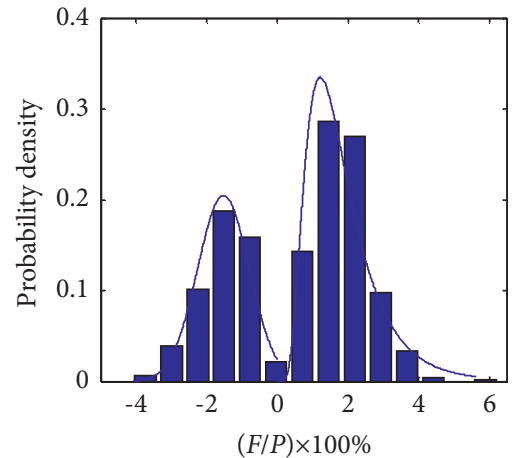

(d)

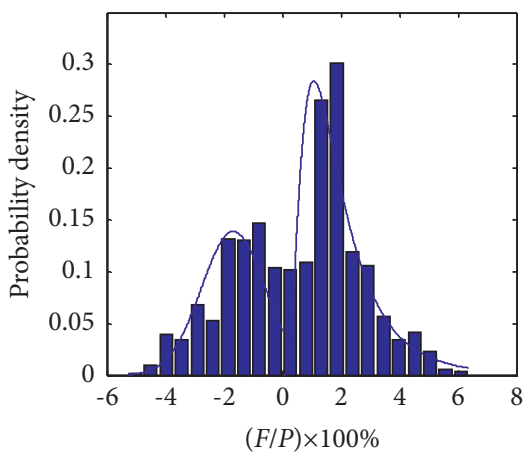

(g)

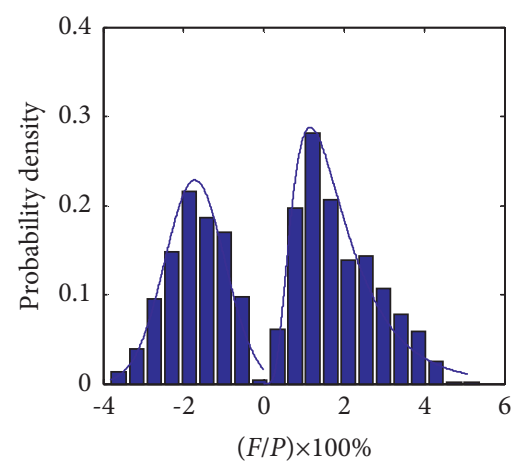

(j)

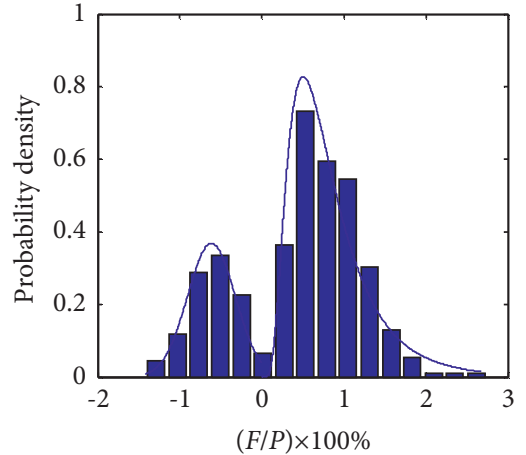

(b)

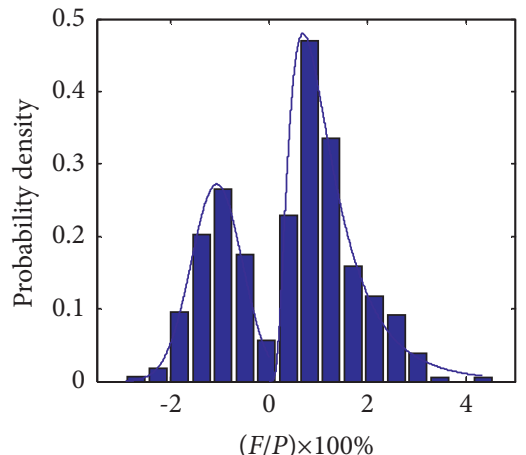

(e)

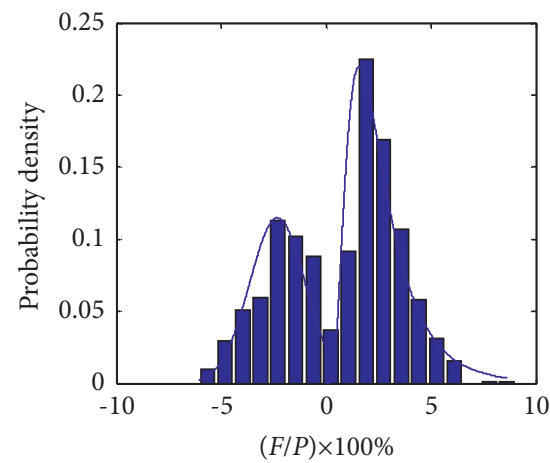

(h)

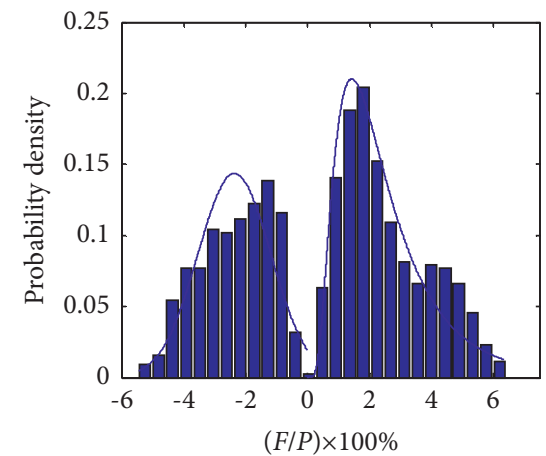

(k)

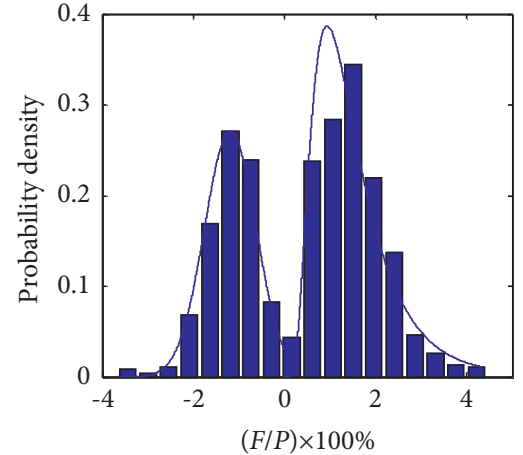

(c)

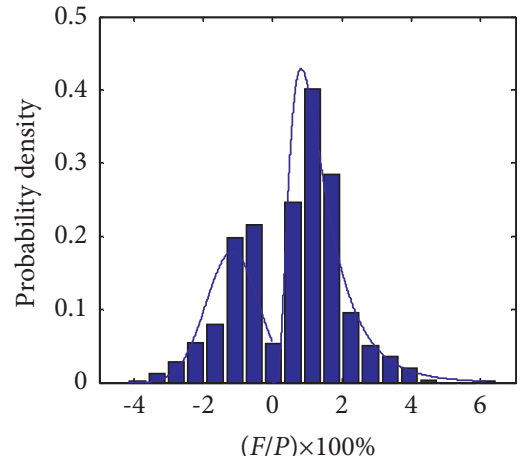

(f)

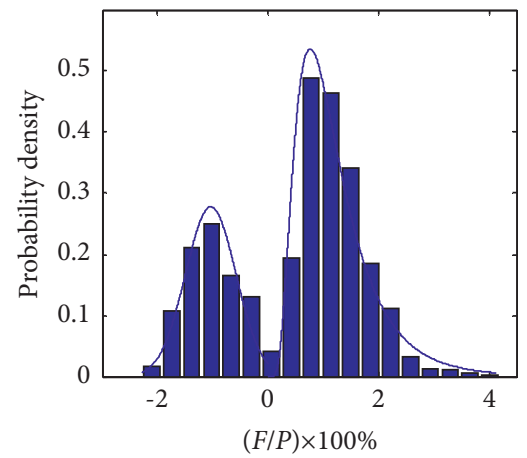

(i)

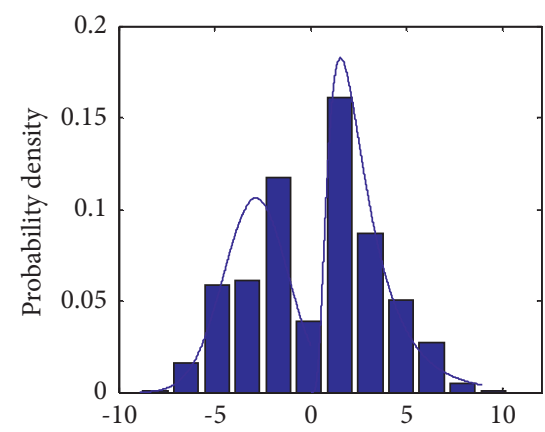

$(F / P) \times 100 \%$

(l)

Figure 4: Probability density figures of $F / P$ for horizontal braces located at $0.6 L$. (a) $\lambda_{c}=50$ and $n=4$. (b) $\lambda_{c}=50$ and $n=6$. (c) $\lambda_{c}=50$ and $n=8$. (d) $\lambda_{c}=50$ and $n=10$. (e) $\lambda_{c}=75$ and $n=4$. (f) $\lambda_{c}=75$ and $n=6$. (g) $\lambda_{c}=75$ and $n=8$. (h) $\lambda_{c}=75$ and $n=10$. (i) $\lambda_{c}=100$ and $n=4$. (j) $\lambda_{c}=100$ and $n=6$. (k) $\lambda_{c}=100$ and $n=8$. (l) $\lambda_{c}=100$ and $n=10$. 


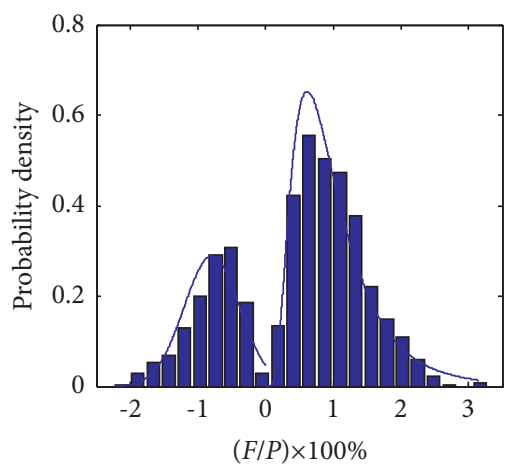

(a)

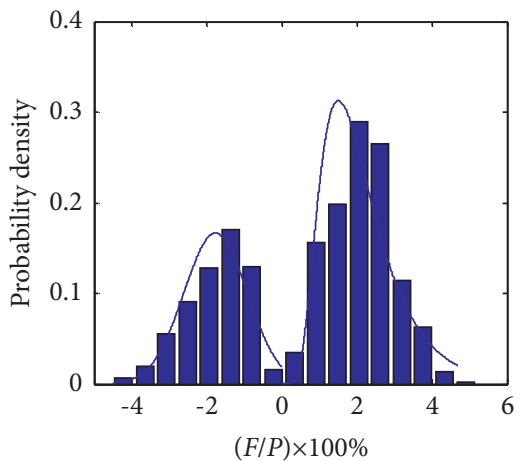

(d)

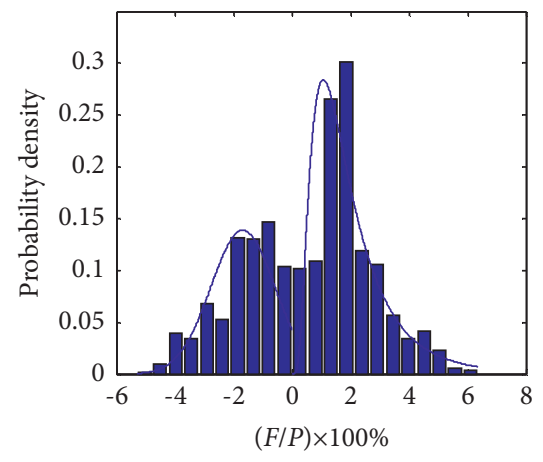

(g)

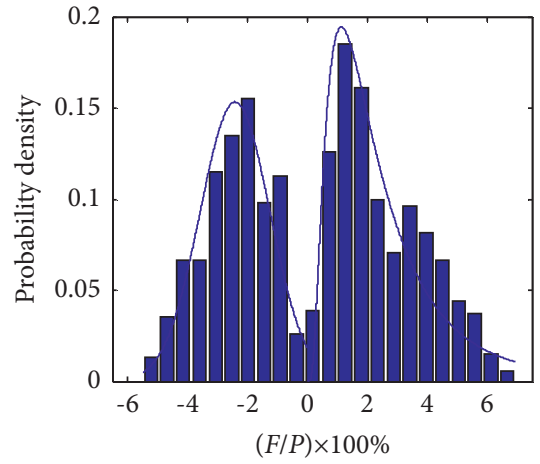

(j)

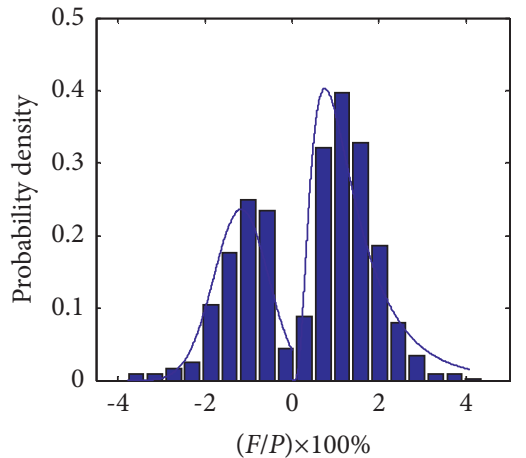

(b)

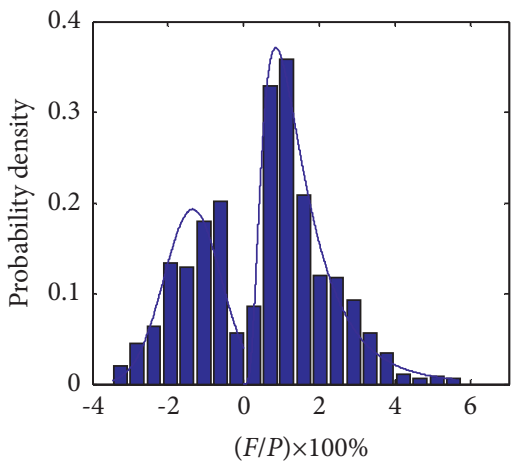

(e)

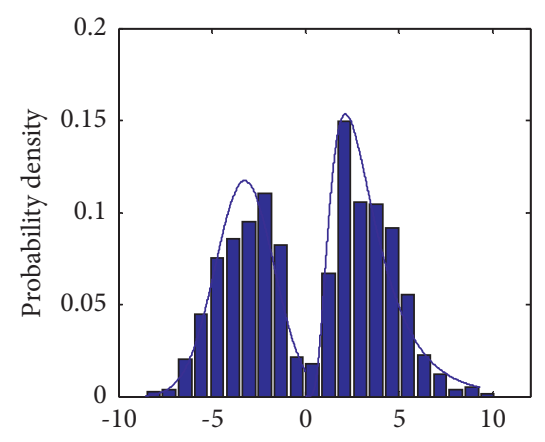

$(F / P) \times 100 \%$

(h)

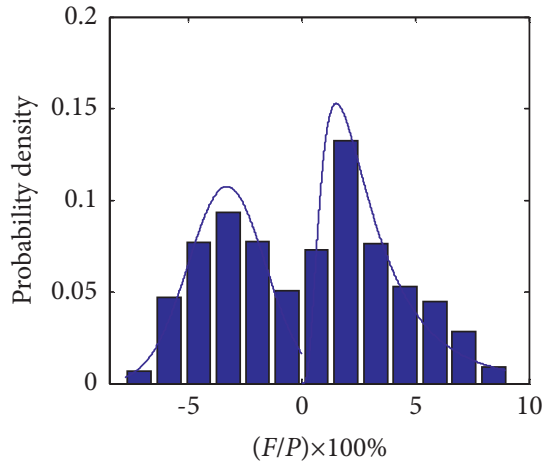

(k)

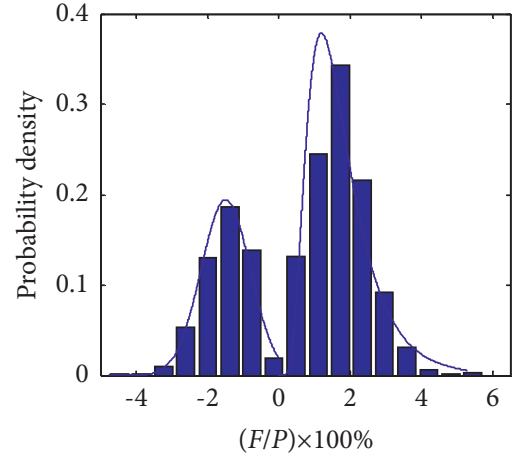

(c)

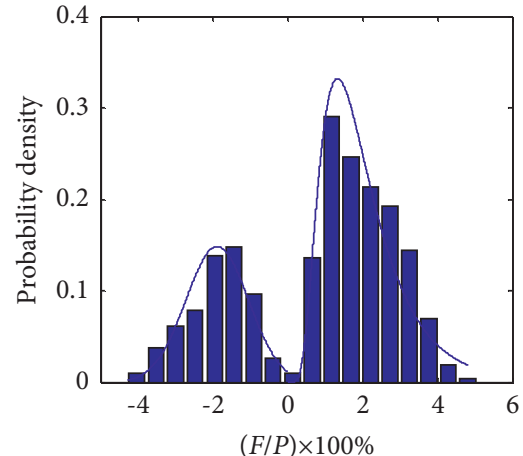

(f)

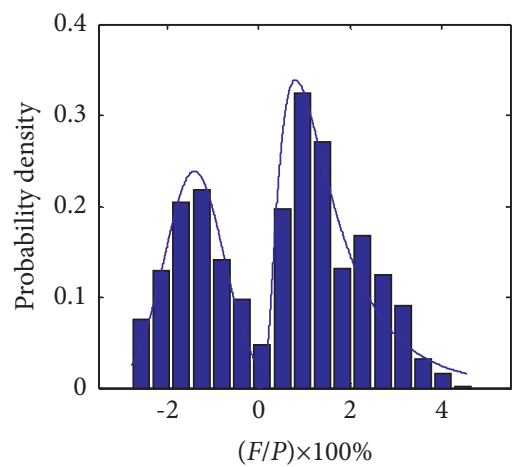

(i)

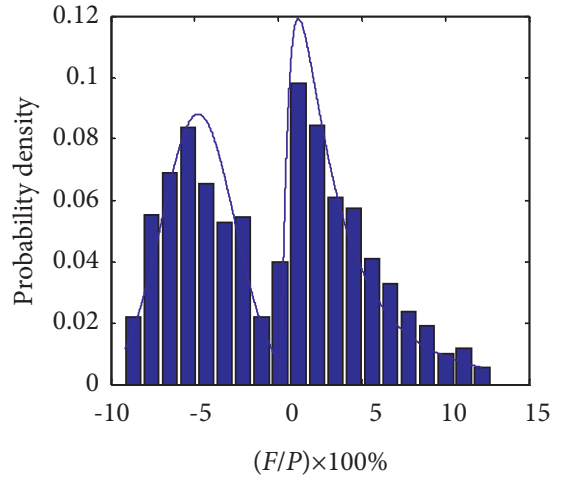

(1)

Figure 5: Probability density figures of $F / P$ for horizontal braces located at $0.7 L$. (a) $\lambda_{c}=50$ and $n=4$. (b) $\lambda_{c}=50$ and $n=6$. (c) $\lambda_{c}=50$ and $n=8$. (d) $\lambda_{c}=50$ and $n=10$. (e) $\lambda_{c}=75$ and $n=4$. (f) $\lambda_{c}=75$ and $n=6$. (g) $\lambda_{c}=75$ and $n=8$. (h) $\lambda_{c}=75$ and $n=10$. (i) $\lambda_{c}=100$ and $n=4$. (j) $\lambda_{c}=100$ and $n=6$. (k) $\lambda_{c}=100$ and $n=8$. (l) $\lambda_{c}=100$ and $n=10$. 
tension. The ordinates of these figures show the relative frequency of various $(F / P) \times 100$ (shown as abscissas). The area of each single blue rectangle represents the probability of that abscissa value being calculated by the finite element analysis, and the sum of all the rectangular areas is equal to 1 . The solid lines represent the theoretical probability density functions that are chosen to fit the data.

5.2. Probability Density Figures of F/P. The probability density function of $F / P$ is given by

$$
f\left(x, a_{1}, \mu, \sigma, \mu_{\text {in }}, \sigma_{\text {in }}\right)=\left\{\begin{array}{l}
\frac{a_{1}}{\sqrt{2 \pi} \sigma} \exp \left[-\frac{1}{2}\left(\frac{x-\mu}{\sigma}\right)^{2}\right], \quad x \leq 0, \\
\frac{\left(1-a_{1}\right)}{\sqrt{2 \pi} \sigma_{\text {in }} x} \exp \left[-\frac{1}{2}\left(\frac{\operatorname{In} x-\mu_{\text {in }}}{\sigma_{\text {in }}}\right)^{2}\right], \quad x>0,
\end{array}\right.
$$

and the distribution function of $F / P$ is

$$
F\left(x, a_{1}, \mu, \sigma, \mu_{\mathrm{in}}, \sigma_{\mathrm{in}}\right)=\left\{\begin{array}{l}
\frac{a_{1}}{\sqrt{2 \pi} \sigma} \int_{-\infty}^{x} e^{-(1 / 2)(t-\mu / \sigma)^{2}} \mathrm{~d} t, \quad x \leq 0, \\
\frac{a_{1}}{\sqrt{2 \pi} \sigma} \int_{-\infty}^{0} e^{-(1 / 2)(t-\mu / \sigma)^{2}} \mathrm{~d} t+\frac{\left(1-a_{1}\right)}{\sqrt{2 \pi} \sigma_{\text {in }}} \int_{0^{+}}^{x} \frac{1}{t} e^{-(1 / 2)\left(\ln t-\mu_{\mathrm{in}} / \sigma_{\text {in }}\right)^{2}} \mathrm{~d} t, \quad x>0,
\end{array}\right.
$$

where $a_{1}$ is the ratio of the number of negative value data over the number of the total data; $\mu_{\text {in }}$ and $\sigma_{\text {in }}$ are the mean value and the mean square deviation of the logarithm of positive value data, respectively; and $\mu$ and $\sigma$ are the mean value and the mean square deviation of negative value data, respectively. The statistical results of various $(F / P) \times 100$ for the horizontal braces located at $0.6 \mathrm{~L}$ and $0.7 \mathrm{~L}$ are shown in Table 3, respectively.

\subsection{Design Forces of Horizontal Braces Unlocated at Middle of} Columns. According to the distribution functions $F(x)$, the $F / P$ ratios can be predicted to a certain significance level, say, $\alpha$. The significance level was selected as $\alpha=0.05$ in this study. Then, the characteristic values $F_{n} / P$ are taken as the horizontal bracing force with a $95 \%$ guarantee rate (see Figure 6).

In order to provide full support for longitudinal columns in the row, $F_{n} / P$ is multiplied by a coefficient of 1.2 , and $1.2 \times F_{n} / P$ is taken as the design horizontal bracing forces. Table 3 summarizes $F_{n} / P$ and $1.2 \times F_{n} / P$ for the horizontal braces located at $0.6 \mathrm{~L}$ and $0.7 \mathrm{~L}$.

\section{Design Recommendations}

Table 3 summarizes $1.2 \times F_{n} / P$ for the horizontal braces located at $0.6 L$ and $0.7 L$ with $n=4,6,8,10$ and $\lambda_{c}=50,75$, 100 , respectively. It should be noted that $1.2 \times F_{n} / P$ increases with an increase of $\lambda_{c}$, and the same result was obtained in reference [8]. Furthermore, according to different $\lambda_{c}$, $1.2 \times F_{n} / P$ may be approximated as follows:

(1) The design formulas of horizontal braces located at $0.6 L$ are

$$
\frac{F_{n}}{P}= \begin{cases}\frac{n}{100}(0.48+0.001 n), & \lambda_{c}=50 \\ \frac{n}{100}(0.45+0.020 n), & \lambda_{c}=75 \\ \frac{n}{100}(0.52+0.028 n), & \lambda_{c}=100 .\end{cases}
$$

(2) The design formulas of horizontal braces located at $0.7 \mathrm{~L}$ are

$$
\frac{F_{n}}{P}= \begin{cases}\frac{n}{100}(0.6+0.0015 n), & \lambda_{c}=50, \\ \frac{n}{100}(0.71+0.021 n), & \lambda_{c}=75, \\ \frac{n}{100}(0.75+0.037 n), & \lambda_{c}=100 .\end{cases}
$$

Figures 7 and 8 show the comparisons between equations (11) and (12), and the results are given in Table 3. It is suggested that equations (11) and (12) may be used in engineering practice for the horizontal braces located at $0.6 \mathrm{~L}$ and $0.7 L$, respectively.

\section{Comparison with Mid-Height Horizontal Bracing Forces}

7.1. Comparison with Previous Study. In reference [8], the mid-height horizontal bracing forces were proposed according to the same research method adopted in this study. Comparison among various $1.2 \times F_{n} / P$ is shown in Table 4, and the variation of the ratios is also plotted in Figure 9. It is shown that the ratios of $1.2 \times F_{n} / P$ for the horizontal braces at $0.7 L$ are the largest, followed by the ratios of $1.2 \times F_{n} / P$ for the horizontal braces at $0.5 \mathrm{~L}$, and the ratios of $1.2 \times F_{n} / P$ for the horizontal braces at $0.6 \mathrm{~L}$ are the smallest. The reasons are summarized as follows: when the horizontal braces are located at $0.6 \mathrm{~L}$, the effective length of lower columns can be increased, so that the ultimate load $P$ and horizontal bracing forces $F$ are lower than those with the horizontal braces located at $0.5 \mathrm{~L}$, and the relatively low ultimate load $P$ of the former more significantly decreases its horizontal bracing force $F$, which eventually results in the ratios of $1.2 \times F_{n} / P$ with the horizontal braces at $0.6 \mathrm{~L}$ being lower than the ratios of $1.2 \times F_{n} / P$ with the horizontal braces at $0.5 L$; when the horizontal braces are located at $0.7 \mathrm{~L}$, the effective length of 
TABLe 3: Statistical results of $F / P \times 100$ and $F_{n} / P^{*}$.

\begin{tabular}{|c|c|c|c|c|c|c|c|c|c|}
\hline \multicolumn{5}{|c|}{ Horizontal braces located at $0.6 \mathrm{~L}$} & \multicolumn{5}{|c|}{ Horizontal braces located at $0.7 \mathrm{~L}$} \\
\hline$\lambda_{c}$ & $n$ & Statistical character & $F_{n} / P(\%)$ & $1.2 \times F_{n} / P(\%)$ & $\lambda_{c}$ & $n$ & Statistical character & $F_{n} / P(\%)$ & $1.2 \times F_{n} / P(\%)$ \\
\hline 50 & 4 & $\begin{array}{c}\mu=-2.0375 ; \sigma=1.0702 \\
\mu_{\text {In }}=0.6923 ; \sigma_{\text {In }}=0.3946 \\
a_{1}=0.2300\end{array}$ & 1.63 & 1.96 & 50 & 4 & $\begin{array}{c}\mu=-0.7927 ; \sigma=0.4124 \\
\mu_{\text {In }}=-0.1401 ; \sigma_{\text {In }}=0.5870 \\
a_{1}=0.2980\end{array}$ & 2.03 & 2.44 \\
\hline 50 & 6 & $\begin{array}{c}\mu=-1.1544 ; \sigma=0.5958 \\
\mu_{\text {In }}=0.2089 ; \sigma_{\text {In }}=0.4510 \\
a_{1}=0.2810\end{array}$ & 2.37 & 2.84 & 50 & 6 & $\begin{array}{c}\mu=-1.1693 ; \sigma=0.6279 \\
\mu_{\text {In }}=0.1563 ; \sigma_{\text {In }}=0.6624 \\
a_{1}=0.3720\end{array}$ & 3.05 & 3.66 \\
\hline 50 & 8 & $\begin{array}{c}\mu=-1.1907 ; \sigma=0.5662 \\
\mu_{\text {In }}=0.2647 ; \sigma_{\text {In }}=0.5743 \\
a_{1}=0.3850\end{array}$ & 3.16 & 3.79 & 50 & 8 & $\begin{array}{c}\mu=-1.4877 ; \sigma=0.6906 \\
\mu_{\text {In }}=0.4434 ; \sigma_{\text {In }}=0.5127 \\
a_{1}=0.3360\end{array}$ & 3.96 & 4.75 \\
\hline 50 & 10 & $\begin{array}{c}\mu=-1.5193 ; \sigma=0.7332 \\
\mu_{\text {In }}=0.4805 ; \sigma_{\text {In }}=0.5294 \\
a_{1}=0.3760\end{array}$ & 4.03 & 4.84 & 50 & 10 & $\begin{array}{c}\mu=-1.7635 ; \sigma=0.8433 \\
\mu_{\text {In }}=0.6485 ; \sigma_{\text {In }}=0.4866 \\
a_{1}=0.3520\end{array}$ & 5.13 & 6.15 \\
\hline 75 & 4 & $\begin{array}{c}\mu=-1.0674 ; \sigma=0.5176 \\
\mu_{\text {In }}=0.0317 ; \sigma_{\text {In }}=0.6390 \\
a_{1}=0.3530\end{array}$ & 1.87 & 2.24 & 75 & 4 & $\begin{array}{c}\mu=-1.3492 ; \sigma=0.7566 \\
\mu_{\text {In }}=0.2587 ; \sigma_{\text {In }}=0.6496 \\
a_{1}=0.3660\end{array}$ & 2.61 & 3.13 \\
\hline 75 & 6 & $\begin{array}{c}\mu=-1.1134 ; \sigma=0.7718 \\
\mu_{\text {In }}=-0.0331 ; \sigma_{\text {In }}=0.8046 \\
a_{1}=0.3060\end{array}$ & 2.88 & 3.46 & 75 & 6 & $\begin{array}{c}\mu=-1.8843 ; \sigma=0.8356 \\
\mu_{\text {In }}=0.5768 ; \sigma_{\text {In }}=0.5375 \\
a_{1}=0.3110\end{array}$ & 4.21 & 5.05 \\
\hline 75 & 8 & $\begin{array}{c}\mu=-1.9497 ; \sigma=1.1104 \\
\mu_{\text {In }}=0.6112 ; \sigma_{\text {In }}=0.6170 \\
a_{1}=0.3910\end{array}$ & 3.85 & 4.62 & 75 & 8 & $\begin{array}{c}\mu=-2.4379 ; \sigma=1.1773 \\
\mu_{\text {In }}=0.7872 ; \sigma_{\text {In }}=0.5883 \\
a_{1}=0.4260\end{array}$ & 5.78 & 6.94 \\
\hline 75 & 10 & $\begin{array}{c}\mu=-2.3161 ; \sigma=1.3239 \\
\mu_{\text {In }}=0.8144 ; \sigma_{\text {In }}=0.5938 \\
a_{1}=0.3810\end{array}$ & 5.48 & 6.58 & 75 & 10 & $\begin{array}{c}\mu=-3.2291 ; \sigma=1.5906 \\
\mu_{\text {In }}=1.0570 ; \sigma_{\text {In }}=0.5564 \\
a_{1}=0.4610\end{array}$ & 7.66 & 9.19 \\
\hline 100 & 4 & $\begin{array}{c}\mu=-0.9750 ; \sigma=0.4261 \\
\mu_{\text {In }}=-0.1504 ; \sigma_{\text {In }}=0.5849 \\
a_{1}=0.3720\end{array}$ & 2.33 & 2.79 & 100 & 4 & $\begin{array}{c}\mu=-1.4045 ; \sigma=0.6492 \\
\mu_{\text {In }}=0.2742 ; \sigma_{\text {In }}=0.6987 \\
a_{1}=0.3880\end{array}$ & 3.03 & 3.63 \\
\hline 100 & 6 & $\begin{array}{c}\mu=-1.7184 ; \sigma=0.7460 \\
\mu_{\mathrm{In}}=0.4839 ; \sigma_{\mathrm{In}}=0.5801 \\
a_{1}=0.4270 \\
\mu=-2.3836 ; \sigma=1.1715\end{array}$ & 3.3 & 3.96 & 100 & 6 & $\begin{array}{c}\mu=-2.5231 ; \sigma=1.1984 \\
\mu_{\text {In }}=0.7677 ; \sigma_{\text {In }}=0.7717 \\
a_{1}=0.4480 \\
\mu=-3.3931 ; \sigma=1.8379\end{array}$ & 4.88 & 5.85 \\
\hline 100 & 8 & $\begin{array}{c}\mu_{\text {In }}=0.7768 ; \sigma_{\text {In }}=0.6407 \\
a_{1}=0.4240\end{array}$ & 4.82 & 5.78 & 100 & 8 & $\begin{array}{c}\mu_{\text {In }}=1.0623 ; \sigma_{\text {In }}=0.7615 \\
a_{1}=0.4580\end{array}$ & 6.97 & 8.36 \\
\hline 100 & 10 & $\begin{array}{c}\mu=-2.8440 ; \sigma=1.4411 \\
\mu_{\text {In }}=0.9566 ; \sigma_{\text {In }}=0.6333 \\
a_{1}=0.4340\end{array}$ & 6.75 & 8.1 & 100 & 10 & $\begin{array}{c}\mu=-4.3562 ; \sigma=2.5071 \\
\mu_{\text {In }}=1.2740 ; \sigma_{\text {In }}=0.7612 \\
a_{1}=0.4760\end{array}$ & 9.39 & 11.27 \\
\hline
\end{tabular}

${ }^{*} F_{n} / P$ : refer to Figure 5 for the definition of the characteristic value.

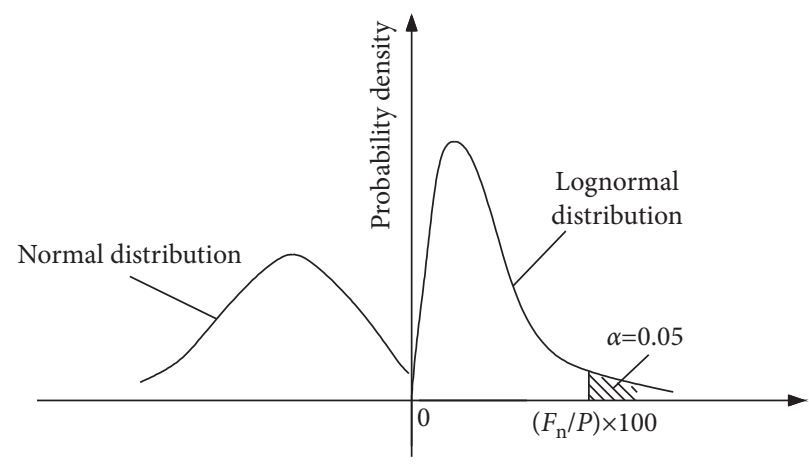

$(F / P) \times 100$

Figure 6: The characteristic values at $\alpha=0.05$. 


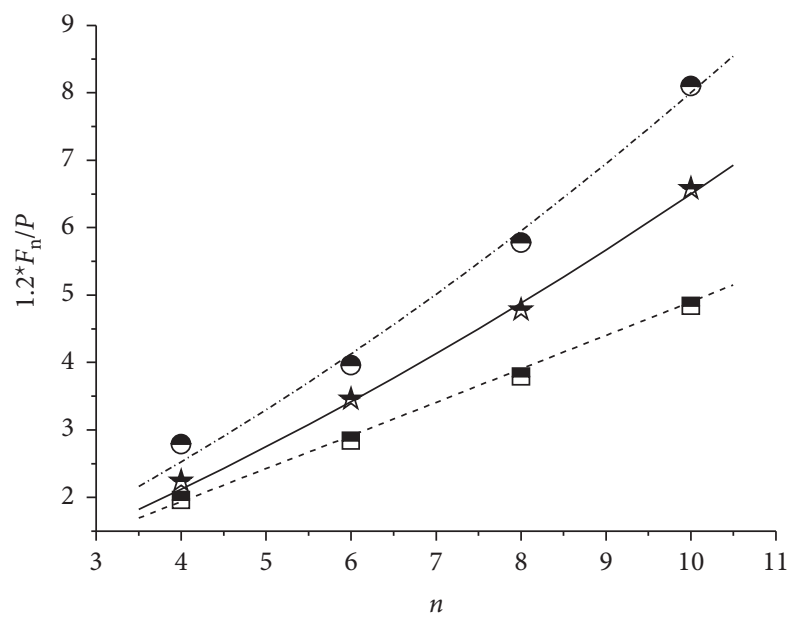

- Table 3 with horizontal braces at $0.6 L$ for $\lambda_{\mathrm{c}}=50$

ฟ Table3 with horizontal braces at $0.6 \mathrm{~L}$ for $\lambda_{\mathrm{c}}=75$

- Table3 with horizontal braces at $0.6 L$ for $\lambda_{\mathrm{c}}=100$

- - - Equation (11) for $\lambda_{\mathrm{c}}=50$

— Equation (11) for $\lambda_{c}=75$

.... Equation (11) for $\lambda_{\mathrm{c}}=100$

FIgURE 7: Variation in $1.2 \times F_{n} /(P)$ for the horizontal braces located at $0.6 L$ against $n$.

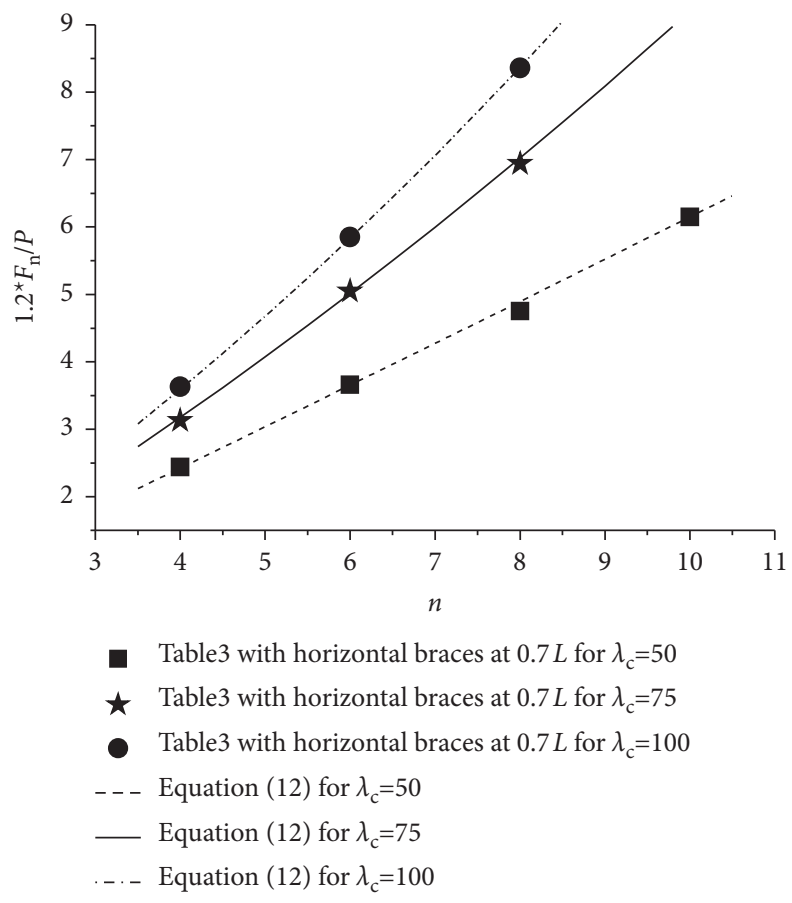

Figure 8: Variation in $1.2 \times F_{n} / P$ for the horizontal braces located at $0.7 L$ against $n$.

lower columns can be further increased, so that the ultimate load $P$ decreases much more, but horizontal bracing force $F$ which is needed to maintain the longitudinal stability of the braced columns decreases much less, which eventually results in the ratios of $1.2 \times F_{n} / P$ with the horizontal braces at $0.7 \mathrm{~L}$ being higher than the ratios of $1.2 \times F_{n} / P$ with the horizontal braces at $0.5 L$.
7.2. Comparison with Relevant Codes. GB50017-2017 [18], Eurocode 3-1992 [19], and AS4100-1998 [20] specify the mid-height horizontal bracing forces of the column-bracing system which are shown in Table 4 . It was found in reference [17] that the mid-height horizontal bracing forces proposed by considering the random initial geometric imperfections were smaller than those given in GB50017-2017, Eurocode 3, 
TABle 4: Comparison of $1.2 \times F_{n} / P$ values (\%).

\begin{tabular}{|c|c|c|c|c|c|}
\hline Horizontal brace location & $\lambda_{c}$ & $n=4$ & $n=6$ & $n=8$ & $n=10$ \\
\hline \multirow{6}{*}{$0.5 L$} & 50 & 2.28 & 3.18 & 4.18 & 5.16 \\
\hline & 75 & 2.71 & 4.44 & 6.12 & 8.16 \\
\hline & 100 & 3.02 & 5.10 & 7.26 & 9.72 \\
\hline & GB50017 & 4.67 & 6.67 & 8.67 & - \\
\hline & Eurocode 3 & 5.81 & 8.06 & 10.27 & 12.46 \\
\hline & AS4100 & 6.25 & 8.75 & 11.25 & - \\
\hline \multirow{3}{*}{$0.6 L$} & 50 & 1.96 & 2.84 & 3.79 & 4.84 \\
\hline & 75 & 2.24 & 3.46 & 4.62 & 6.58 \\
\hline & 100 & 2.79 & 3.96 & 5.78 & 8.10 \\
\hline \multirow{3}{*}{$0.7 L$} & 50 & 2.44 & 3.66 & 4.75 & $\overline{6.15}$ \\
\hline & 75 & 3.13 & 5.05 & 6.94 & 9.19 \\
\hline & 100 & 3.63 & 5.85 & 8.36 & 11.27 \\
\hline
\end{tabular}

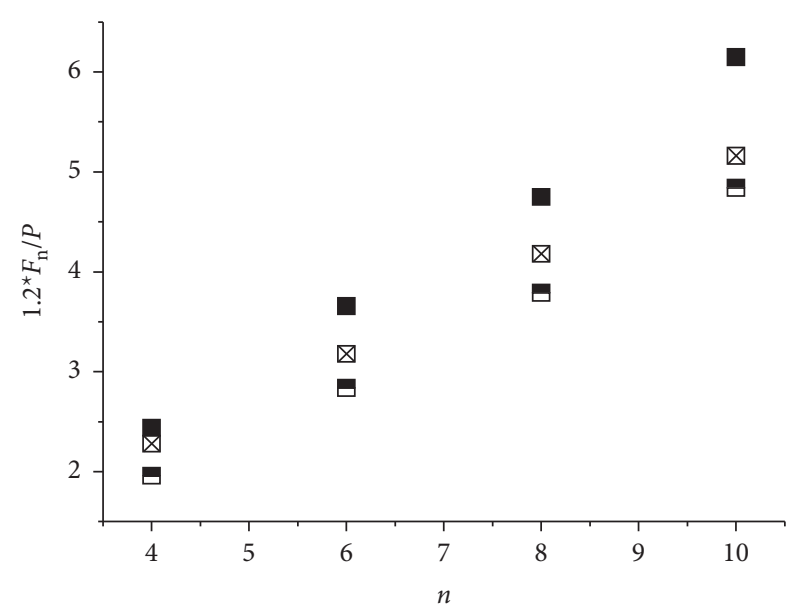

凶 Horizontal braces at $0.5 \mathrm{~L}$

- Horizontal braces at $0.6 \mathrm{~L}$

- Horizontal braces at $0.7 \mathrm{~L}$

(a)

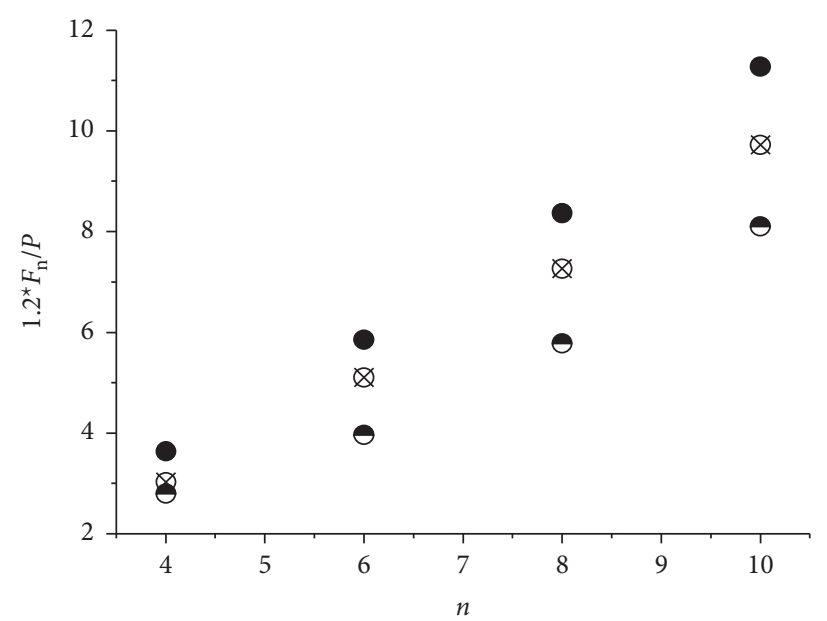

(b)

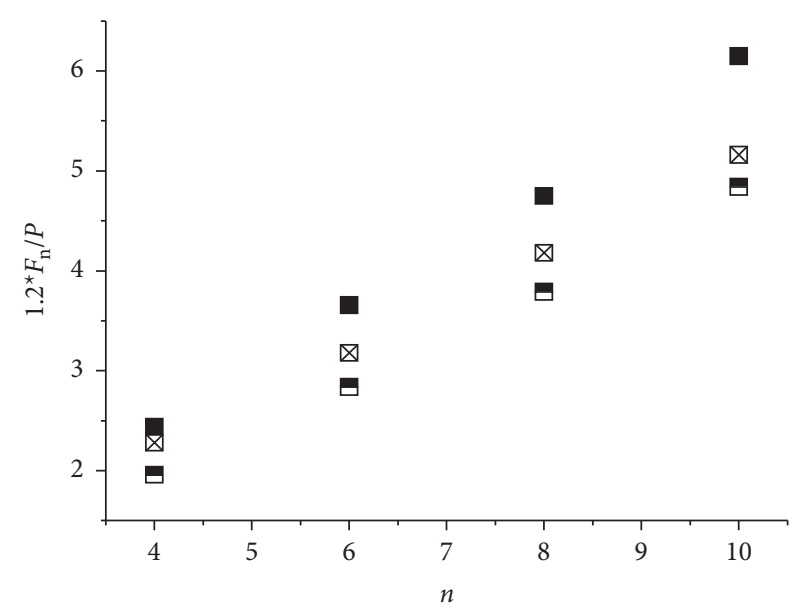

\Horizontal braces at $0.5 \mathrm{~L}$

- Horizontal braces at $0.6 \mathrm{~L}$

- Horizontal braces at $0.7 \mathrm{~L}$

$叉$ Horizontal braces at $0.5 \mathrm{~L}$

- Horizontal braces at $0.6 \mathrm{~L}$

- Horizontal braces at $0.7 \mathrm{~L}$

(c)

Figure 9: Comparison of $1.2 \times F_{n} / P$ among various horizontal brace locations. (a) $\lambda_{c}=50$. (b) $\lambda_{c}=75$. (c) $\lambda_{c}=100$. 


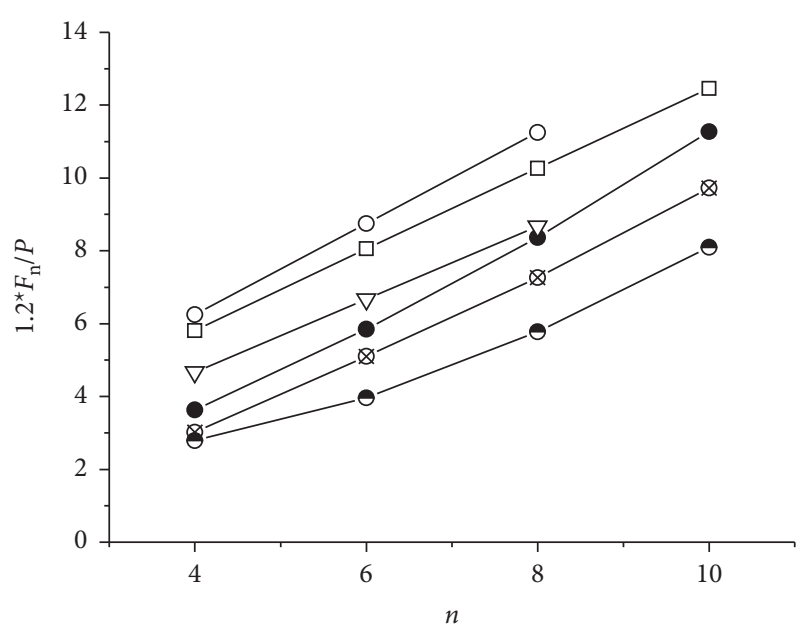

- Proposed method for horizontal braces at $0.5 \mathrm{~L}$

- Proposed method for horizontal braces at $0.6 \mathrm{~L}$

- - Proposed method for horizontal braces at $0.7 \mathrm{~L}$

$\neg-$ GB50017-2017 for horizontal braces at $0.5 \mathrm{~L}$

$\neg \square$ Eurocode 3-1992 for horizontal braces at $0.5 \mathrm{~L}$

-O- AS4100-1998 for horizontal braces at $0.5 \mathrm{~L}$

Figure 10: Comparison of $F_{n} / P$ values for $\lambda_{c}=100$ with relevant codes.

and AS4100-1998. Although the design forces of horizontal braces located at $0.7 \mathrm{~L}$ from the proposed method are larger than the mid-height horizontal bracing forces from the same proposed method, they are still smaller than the mid-height horizontal bracing forces stipulated in GB50017-2017, Eurocode 3-1992, and AS4100-1998. As the horizontal bracing forces increase with an increase of $\lambda_{c}$, the comparison of horizontal bracing forces between the proposed method and the relevant codes is plotted in Figure 10 when $\lambda_{c}$ is equal to 100 .

\section{Conclusions}

The design forces of the horizontal braces unlocated at middle of columns were determined by Monte Carlo simulation, finite element analysis, and probability statistics, in which the random initial geometric imperfections of both the columns and the horizontal braces were well considered. The conclusions are summarized as follows:

(1) The structural performance of the column-bracing system resulting from real random initial imperfections was well predicted by the Monte Carlo method. When the ultimate loads of the braced columns are reached, the horizontal braces used to reduce the out-of-plane effective column lengths may be in compression or in tension, i.e., the horizontal bracing forces have randomness.

(2) The probability density function of horizontal bracing forces unlocated at middle of columns was established by probability statistics, the practical design formulas for horizontal bracing forces unlocated at middle of columns were also proposed, and it was found that the design forces of horizontal braces located at 0.6 column height are smaller than the mid-height horizontal bracing forces in the previous study while the design forces of horizontal braces located at 0.7 column height are larger than the mid-height horizontal bracing forces in the previous study.

(3) As the random initial geometric imperfections of the columns and the horizontal braces were well considered, the proposed design forces of the horizontal braces located and unlocated at middle of columns were both decreased to more reasonable values which were smaller than the mid-height horizontal bracing forces stipulated in GB50017-2017, Eurocode 3-1992, and AS4100-1998.

\section{Data Availability}

The data used to support the findings of this study are available from the corresponding author upon request.

\section{Conflicts of Interest}

The authors declare that they have no conflicts of interest.

\section{Acknowledgments}

This study was supported by the National Natural Science Foundation of China (51008055) and the Natural Science Foundation of Heilongjiang Province (LH2019E006).

\section{References}

[1] G. Winter, "Lateral bracing of columns and beams," Journal of Structural Division ASCE, vol. 84, pp. 1-22, 1958.

[2] R. H. Plaut, "Lateral bracing forces in columns with two unequal spans," Journal of Structural Engineering, vol. 119, no. 10, pp. 2896-2913, 1993.

[3] J. A. Yura, "Winter's bracing approach revised," Engineering Structures, vol. 18, no. 10, pp. 821-825, 1996.

[4] H. Gil and J. A. Yura, "Bracing requirements of inelastic columns," Journal of Constructional Steel Research, vol. 51, pp. 1-19, 1999.

[5] G. S. Tong and S. P. Chen, "Design requirements for bracings between columns," Industrial Construction, vol. 33, no. 5, pp. 9-12, 2003.

[6] D. Li, Stability Analysis and Bracing Requirements of Longitudinal Braced Frame, Doctoral Thesis, Zhejiang University, Hangzhou, China, 2005.

[7] Y. C. Zhang, J. Y. Zhao, and W. Y. Zhang, "Parametric studies on inter-column brace forces," Advances in Structural Engineering, vol. 11, no. 3, pp. 305-309, 2008.

[8] J. Y. Zhao, Y. C. Zhang, and Y. Y. Lin, "Study on mid-height horizontal bracing forces considering random initial geometric imperfections," Journal of Constructional Steel Research, vol. 92, no. 1, pp. 55-66, 2014.

[9] R. S. Mohammad and G. Mehrdad, "Effect of random distribution of member length imperfection on collapse behaviour and reliability of flat double-layer grid space structures," Advances in Structural Engineering, vol. 18, no. 9, pp. 1475-1485, 2015.

[10] D. Bach, O. Makoto, and Y. Makoto, "Bayesian optimization for robust design of steel frames with joint and individual 
probabilistic constraints," Engineering Structures, vol. 245, no. 1, 2021.

[11] K. M. Reza, M. Maryam, M. Masoud et al., "Comparison between uniform deformation method and Genetic Algorithm for optimizing mechanical properties of dampers," Earthquakes and Structures, vol. 14, no. 1, pp. 1-10, 2018.

[12] A. V. Bergami and C. Nuti, "A design procedure of dissipative braces for seismic upgrading structures," Earthquake \& Structures, vol. 4, no. 9, pp. 85-108, 2013.

[13] Z. J. Xu, Monte Carlo Method, Shanghai Technology and Science Publishing House, Shanghai, China, 1985.

[14] A. S. Nowak and K. R. Collins, Reliability of Structures, The McGraw-Hill Education (Asia) Companies Press, NY, USA, 2012.

[15] Y. C. Zhang, L. Jin, Y. S. Shao, and J. Y. Zhao, "Practical advanced design considering random distribution of initial geometric imperfections," Advances in Structural Engineering, vol. 14, no. 3, pp. 379-389, 2011.

[16] G. S. Tong and S. F. Chen, "Design forces of horizontal intercolumn braces," Journal of Constructional Steel Research, vol. 7, pp. 363-370, 1987.

[17] Gb50205-2001, Code for Acceptance of Construction Quality of Steel Structures, Chinese Planning Press, Beijing, China, 2001.

[18] Gb50017-2017, Code for Design of Steel Structures, Chinese Planning Press, Beijing, China, 2017.

[19] Eurocode 3, Design of Steel Structures, Part 1.1: General Rules and Rules for Buildings, Commission of European Communities, Brussels, Belgium, 1992.

[20] Australia Standard, Steel Structures (AS4100-1998), Standard Association of Australia, Sydney, Australia, 1998. 